\title{
Antibiotic resistance profile of gram negative bacilli isolated from ants in selected level 1 hospitals in Davao City
}

\author{
Anna-Lee B. Bandoy ${ }^{1 *}$, Julie J. Tiu ${ }^{2}$ \\ ${ }^{1}$ University of the Immaculate Conception, Davao City, Philippines \\ ${ }^{2}$ San Pedro College, Davao City, Philippines
}

\author{
Key Words: \\ Microbiology \\ Antibiotic resistance \\ Ants \\ Hospitals \\ Davao city
}

Received: 4 May 2017

Accepted: 22 June 2017

Published: 30 June 2017

\begin{abstract}
The occurrence of increasing hospital-acquired infections and the reports of the occurrence of ants in the hospital had become a research focus owing to the exposure of patients and health professionals to risk associated with insects. The study aimed to evaluate the potential of ants as mechanical vectors of pathogenic bacteria and assess the antibiotic resistance profile of gram-negative bacilli isolated in selected Level one hospitals in Davao City. The study utilized a descriptive design. The researcher collected the ant samples in female, male, and pediatrics wards in the selected Level one hospitals. Afterward, the captured ant species were immersed in double-strength TSB for bacterial cultivation. After distinct pure colonies of bacteria were isolated, they were subjected to bacterial identification and antibacterial susceptibility tests using VITEK 2 Systems. The study's findings suggest that Tapinoma melacephalum, Monomorium pharaonis and Anoplolepis gracile are mechanical vectors of opportunistic pathogen that commonly cause hospital-acquired infections. Moreover, two (2) isolates of E. cloacae from T. melanocephalum and one (1) isolate of E. cloacae from M. pharaonis demonstrated multidrug resistance. Further, the results also suggest the possible poor implementation of sanitation and pest control protocols. The researcher recommends identifying and profiling gram-positive bacteria and exploring the different hospital areas, including critical care units, as sampling points.
\end{abstract}

(C) 2017 The Author(s). Published by TAF Publishing.

\section{INTRODUCTION}

Ants have several mutualistic and parasitic relationships with fungi, bacteria, animals and plants [1] . Ants usually occupy microbe-rich environment and densely populated colonies of related individuals and are most susceptible to infection and rapid disease transmission [2]. The hospital environment is one of the main areas where ants thrive and their presence can facilitate propagation of pathogenic microorganisms [1]. In addition, the eradication of urban ants became a complex task due to their fast adaptation to the environment [3].

With these reports, the occurrence of ants in hospitals has become a research focus owing to the exposure of patients and health professionals to the risks associated with insects. Since ant and bacteria associations have been established in several hospitals worldwide, this has raised concerns about possible role of ants as disease vectors [3]. A study conducted by [4] revealed that ant species namely Tapinoma melanocephalon (Fabricus)

\footnotetext{
${ }^{*}$ Corresponding author: Anna-Lee B. Bandoy

${ }^{\dagger}$ Email: abandoy@uic.edu.ph
} 
and Camponotus viltatus (Forel) have been identified to be carrying bacterial strains of coagulase-positive Staphylococcus, coagulase-negative Staphylococcus and gram-negative bacilli, including antimicrobial drug-resistant strains. Further, studies conducted in hospitals in Brazil have proven the presence of fungi and bacteria in the ant's teguments [5]. Meanwhile, Staphylococcus aureus, Pseudomonas aeruginosa, coagulase-negative Staphylococci, Klebsiella pneumoniae and Escherichia coli were reported as the most frequent bacterial agents involved in hospital-acquired infections [6].

Based on the literature review, ants as disease vectors have yet to be profiled in Asia, specifically in the Philippines. Moreover, according to [7], ant faunas in the Philippines are only partly explored.

Considering the ability of ants as vector of bacteria in hospitals, this study aimed to identify and characterize the presence of bacteria associated with ants and its potential threat and role in the spread of nosocomial infections. Also, this study aimed to evaluate the antibiotic resistance profile of gram negative bacilli isolated from ants in selected Level one hospitals in Davao City, Philippines.

\section{FRAMEWORK}

This study was based primarily on the potential of ants as mechanical vector of bacterial disease agents in hospitals $[8,9,10]$. Ants have been identified to carry microorganisms including Staphylococcus, Escherichia, Pseudomonas, Enterobacter, Bacillus, Streptococcus and Klebsiella [11]. Also, according to [3], bacterial species isolated from ants such as Acinetobacter spp, Streptococcus, Gemella and Klebsiella demonstrated multidrug resistance. According to [6], the agents that were usually involved in hospital-acquired infections include Streptococcus spp, Acinetobacter spp, enterococci spp, P. aeruginosa, coagulasenegative staphylococci, S. aureus, B. cereus, Legionella, P. mirabilis, K. pneumoniae, E. coli and $S$. marcescens. And all species in this list were isolated from ants. Hence, this study assessed the potential threat of the presence of ants in the hospital environment and its role in spreading nosocomial infections.

\section{Statement of the Problem}

This study focused on the characterization of isolated gram negative bacilli and their antibiotic resistance profile from ants in selected Level one hospitals in Davao City. The study also aimed to identify the different species of ants collected from the selected level one hospitals and the different bacterial species isolated from the captured ants.

\section{RESEARCH METHODOLOGY}

\section{Research Design}

This study employed a descriptive method and qualitative design, where the researcher prepared ant baits and strategically placed them in the hospital area to survey the different ant species that infest the different level 1 hospitals in the setting. The ant species that were collected from the ant baits were subjected to microbiological tests to isolate, identify and assess the antibiotic resistance profile of the harbored gram negative bacteria using the VITEK 2 Systems.

\section{Setting}

The study was conducted in two settings. First, the captured ant samples were collected in three different level 1 hospitals in Davao City. The setting of the study was conducted in a peri-urban community. Second, the ant samples that were collected from the ant baits 
were transported to the UIC Clinical Laboratory and Training Center where procedures and tests for isolation and preliminary identification of bacteria were performed. Afterwards, pure culture isolates of bacterial species were transported to Davao Regional Medical Center for confirmatory identification and antibiotic susceptibility testing via VITEK 2 systems testing.

\section{Subjects}

This study described and identified the ants that were collected from different level 1 hospitals in Davao City. A sample of each ant type was sent to the Philippine National Museum for species verification. The study was limited only to the isolation and antibiotic resistance profiling of gram negative bacilli.

\section{Measures}

For capturing the ants, an improvised ant collection tool based on the study of [12] was used. for initially identifying the isolated organism, a conventional method using panel of biochemical tests as described by [13] was used. For confirming the identification of the isolated bacteria and assessing their antibiotic resistance profile, pure culture samples were subjected to VITEK 2 Systems Version 07.01 testing.

\section{Procedures}

\section{Ant capture}

The study employed a purposive sampling method with samples taken only from three different primary hospitals. The study of [3] and [12] served as the procedural basis of the collection of ant samples with slight modifications. The collection period was conducted during the entire month of April 2017. Samples of ants were collected in weekly intervals for three weeks with traps installed between 1 and 3 PM from the selected collection points of the hospital. The collection points in the primary hospitals were the following: Male Wards, Female Wards and Pediatrics Wards.

The ants were captured in an aseptic condition in traps which were assembled as follows: plastic bottles $(500 \mathrm{ml})$ were cut in half at the middle of the bottle. Then, the upper half was turned upside down and placed in the bottom of the half to form a container with the funnel pointing inward. Each trap contained a non-toxic sterile bait mixture of equal amounts of autoclaved tuna in oils, pineapple and honey-flavored cake. The selection of collection points was based on the wards available in the respective primary hospitals. Moreover, the site of collection with approximately 1 meter diameter was disinfected with $10 \%$ Sodium hypochlorite.

After the sample collection, the openings of the ant traps were sealed using a sterile $4 \times 4$ inch gauze and placed inside a sterile zip lock pack. All samples were labelled appropriately with time and area of collection and placed in a suitable box in an upright position and transported to the laboratory as soon as possible to ensure they are tested on the same day or at least within 24 hours of collection.

All the baits used in the study were sterilized using an autoclave at $121^{\circ} \mathrm{C}$ at $15 \mathrm{psi}$ for 15 minutes. Further, the baits used were subjected to sterility testing. Ant samples for microbiological analyses were composed of a minimum of 10 individuals from each morphological ant species collected using sterilized forceps or tweezers and transferred to vials containing $10 \mathrm{~mL}$ of Double Strength Trypticase Soy Broth. 


\section{Ant speciation}

During the sample collection, the primary investigator was assisted by an entomologist to sort and preliminarily identify the captured ant species. Moreover, for further species identification, 20 individuals from each morphological species were collected and transferred to vials with $70 \%$ ethyl alcohol. Part of the collection was sent to the Philippine National Museum, Manila, Philippines for ant species verification.

\section{Isolation and identification of bacteria from ants}

Ant samples for microbiological analyses were incubated at 36.9 degrees Celsius for 48 hours. After this period, vials without visible bacterial growth were reported as negative and discarded. Further, tubes with visible growth were transferred to primary plates namely: MacConkey Agar and Blood Agar. Afterwards, preliminary identification and characterization of bacterial isolates were performed using light microscopy, gram staining, biochemical tests and manual identification by following the protocol described by [13]. For confirming the identification of bacterial species isolates, pure culture samples of preliminarily identified organisms were subjected to VITEK 2 Systems Version 07.01 testing.

\section{Antibiotic resistance profile}

The isolated bacteria were subjected to the different antibiotic panels using VITEK 2 Systems Version 07.01 based on the EUCAST standards.

\section{DISCUSSION}

Based on the results, the ant species, Tapinoma melanocephalum, Monomorium pharaonis and Anoplolepis gracilipes are mechanical vectors of opportunistic pathogens. These findings support the previous studies conducted by $[3,4,11]$ that ant species especially T. melanocephalum are vector of pathogenic bacteria such as Staphylococcus spp, Pseudomonas spp, Enterobacter spp, Streptococcus spp, Klebsiella spp, and Acinetobacter spp. Further, the factors that may affect the spread of hospital-acquired infections due to the presence of ants as mechanical vectors are the following: the sanitation of the hospital, the type and structural design of the hospital building and the type of ant species involved [9].

TABLE 1. Ant species isolated from hospital A, B and C in Davao city

\begin{tabular}{|c|c|c|c|c|}
\hline & Ant Species & Week 1 & Week 2 & Week 3 \\
\hline \multicolumn{5}{|l|}{ Hospital A } \\
\hline Female Ward & M. pharaonis & $\checkmark$ & $\checkmark$ & $\checkmark$ \\
\hline Male Ward & M. pharaonis & $\checkmark$ & $\checkmark$ & $\checkmark$ \\
\hline Pedia Ward & M. pharaonis & $\checkmark$ & $\checkmark$ & $\checkmark$ \\
\hline \multicolumn{5}{|l|}{ Hospital B } \\
\hline Female Ward & T. melanocephalum & $\checkmark$ & $\checkmark$ & none \\
\hline Male Ward & P. longicornis & $\checkmark$ & none & none \\
\hline Pedia Ward & A. gracilipes & $\checkmark$ & $\checkmark$ & none \\
\hline \multicolumn{5}{|l|}{ Hospital C } \\
\hline \multirow[t]{2}{*}{ Female Ward } & T. melanocephalum & $\checkmark$ & $x$ & none \\
\hline & M. pharaonis & $x$ & $\checkmark$ & none \\
\hline Male Ward & T. melanocephalum & $\checkmark$ & $\checkmark$ & $\checkmark$ \\
\hline Pedia Ward & T. melanocephalum & $\checkmark$ & none & $\checkmark$ \\
\hline Legned: & $\checkmark=$ Present & $x=$ Absent & None $=$ No ant species isolated & \\
\hline
\end{tabular}


As shown in Table 1 Tapinoma melanocephalum, Monomorium pharaonis, Anoplolepis gracilipes and Paratrechina longicornis were the four (4) different ant species collected from the selected Level one hospitals. The variation of the type of ant species infestation to the different hospitals was affected by factors such as the type of food present and environment [14]. The most frequent ant species that were isolated from the three Level one hospitals were T. melanocephalum and M. pharaonis. The increased frequency of these ant species may be attributed to their characteristic of "invasive ant syndrome" [15]. In addition, invasive ants are unicolonial. Unicoloniality is considered as the key attribute responsible for the ecological success of invasive ants. This allows them to obtain advantage over other species in direct encounters and indirect resource allocation such as foranging [16]. Further, the capture of these ant species may be attributed to their behavior of being attracted to sweet foods such as sugars, cakes and syrups that were used as the composition of the baits used in the study. It was also observed as the common type of food in the hospital wards. In addition, all the three Level 1 hospitals were observed to be situated near residential houses and commercial buildings. The increased likelihood of colonization of the said ant species can be attributed to their preference of frequently disturbed habitats according to [17]. Moreover, it was noted that the only ant species collected in hospital A was M. pharaonis, which nests on light sockets, potted plants and wall cracks or crevices and was particularly observed to be present in hospital A. Meanwhile, the highest isolation of T. melanocephalum was in hospital C which nests on the soil, rotten wood, decaying parts of trees or under bark, in plant cavities, houses and was also particularly observed to be present in hospital C.

TABLE 2. Bacterial isolates based on ant species collected

\begin{tabular}{|c|c|c|}
\hline Ant Species & Gram Negative Bacilli & Others \\
\hline \multicolumn{3}{|l|}{ Tapinoma } \\
\hline \multirow{5}{*}{ melanocephalum } & Acinetobacter baumannii & Enterococcus faecalis \\
\hline & Enterobacter cloacae complex & Enterococcus cecorum \\
\hline & Klebsiella oxytoca & Staphylococcus sciuri \\
\hline & Klebsiella pneumoniae subs. pneumoniae & Bacillus spp \\
\hline & Pseudomonas luteola & \\
\hline \multicolumn{3}{|l|}{ Monomorium } \\
\hline \multirow[t]{2}{*}{ pharaonis } & Acinetobacter lwoffii & Staphylococcus xylosus \\
\hline & Enterobacter cloacae complex & Bacillus spp. \\
\hline Anoplolepis gracilipes & & Bacillus spp. \\
\hline Paratrechina & & \\
\hline longicornis & No bacterial species isolated & \\
\hline
\end{tabular}

On the aspect of bacterial isolates per ant species, Table 2 shows that among the 4 ant species, T. melanocephalum has the highest number of bacterial species isolated with a total of 9 different bacterial isolates followed by M. pharaonis with 4 bacterial species isolates. Noticeably, no bacterial species was isolated from P. longicornis which may be attributed to the presence of metapleural gland, a gland that secretes substances that help prevent growth of bacterial and fungal spores on the ants and inside their nests [18]. Although the metapleural gland is considered as an important component in ant's immunity against microorganisms, some ant species are observed to have lost the gland during their evolution [19]. The bacterial species Acinetobacter baumanni, Enterobacter cloacae complex, Enterococcus faecalis, Enterococcus cecorum, Klebsiella pneumonie subs. pneumoniae, Klebsiella oxytoca, Pseudomonas luteola, Staphylococcus sciuri and Bacillus spp, were iso- 
lated from T. melanocephalum. On the other hand, Acinetobacter lwoffii, Enterobacter cloacae complex, Staphylococcus xylosus and Bacillus spp. were isolated from M. pharaonis and only Bacillus spp. was isolated from A. gracilipes. In addition, according to [20] and [13], these bacterial isolates were also commonly seen and isolated from hospital environment including hospital food, respiratory therapy equipment, hospital sink traps, hospital floor and fomites like bed rails, stainless steel trolleys, door handles etc. These findings support the study conducted by $[3,4,11]$ that $T$. melanocephalum, M. pharaonis and A. gracilipes act as mechanical vectors of opportunistic pathogens which commonly cause nosocomial infections. In addition, unicolonial characteristics of T. melanocephalum and M. pharaonis prevents introduction of new genetic material in the supercolony which results in a low level of genetic variation which increases the susceptibility of the ant population to disease. Further, it also increases the contact rates and density of ant individuals which increases the rates of disease transmission [21].

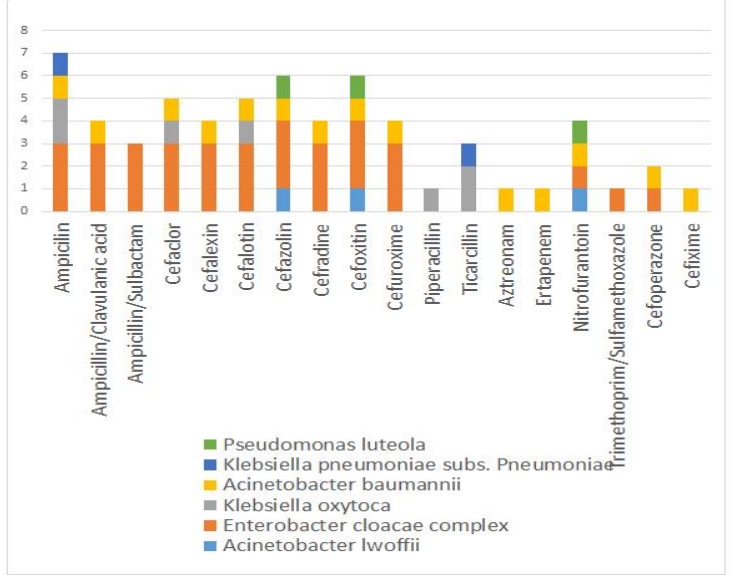

FIGURE 1. Antibiotic resistance profile of the gram negative bacilli isolated from ants

Figure 1 shows that nine (9) Gram negative bacilli isolates from Tapinoma melanophalum and Monomorium pharaonis demonstrated drug resistance to eighteen different antibiotic agents. Remarkably, it was noted that seven (7) out of nine (9) isolates were resistant to Ampicillin, six (6) out of nine (9) were resistant to cefazolin and cefoxitin and five (5) out of nine (9) were resistant to cefaclor and cefalotin. In addition, Table 3 shows

TABLE 3 . Antibiotic resistance profile of gram negative bacilli isolates

\begin{tabular}{lccc}
\hline \hline & Non- MDR & MDR & XDR \\
\hline Hospital A & 1 & 0 & 0 \\
Acinetobacter lwoffii & 0 & 1 & 0 \\
Enterobacter cloacae complex & & & \\
Hospital B & 1 & 0 & 0 \\
Klebsiella oxytoca & & & \\
Hospital C & 1 & 0 & 0 \\
Acinetobacter baumannii & 0 & 2 & 0 \\
Enterobacter cloacae complex & 1 & 0 & 0 \\
Klebsiella pneumoniae subs. pneumoniae & 1 & 0 & 0 \\
Klebsiella oxytoca & 1 & 0 & 0 \\
Pseudomonas luteola & & & \\
\hline \hline
\end{tabular}


that among the 9 gram negative bacilli that were isolated, three isolates of Enterobacter cloacae complex demonstrated multi-drug resistance to drug categories namely penicillin, penicillin + beta-lactamase inhibitors and Non- extended: cephalosporins; 1st and 2nd generation cephalosporins according to the European Committee on Antimicrobial Susceptibility Testing (EUCAST). Notably, among the three E. cloacae complex isolates, one was isolated from M. pharaonis in hospital A and 2 were isolated from T. melanocephalum in hospital C. These results are similar to the findings of [3] in which E. agglomerans, E. amnigenus and E. cloacae isolated from both T. melanocephalum and M. pharaonis demonstrated multi-drug resistance.

Furthermore, according to the Sanitation Code of the Philippines (P.D. 856) Section 20 , all health institutions are mandated to establish pest controls as part of the minimum requirement for sanitary permit. Yet, the researcher was able to collect 4 different ant species as shown in Table 1 in the three different Level 1 hospitals which shows successful ant infestation. This suggests that in spite of the existence and mandate of pest and sanitary protocols in the Level 1 hospitals, the presence of ants demonstrates poor implementation of the hygiene and sanitation standards [22]. Further, poor sanitation of hospital environments increases the likelihood of bacterial colonization and environmental surface contamination which increases the tendency of ants to become mechanical vectors of pathogens. As observed in the study conducted by [23], houses that were cleaned before the ants were collected showed lower bactericidal colonization. Therefore, this demonstrates that contamination risk due to bacteria can be reduced by using hygienic practices.

\section{CONCLUSION}

Based on the findings of the study, it can be concluded that Tapinoma melanocephalum, Monomorium pharaonis and Anoplolepis gracilipes are mechanical vectors of opportunistic pathogens which commonly cause hospital-acquired infections. Also, ants may harbor multi-drug resistant organism. Moreover, the results also suggest that there is a poor implementation of sanitation and pest control protocol in spite of existing mandated laws.

\section{RECOMMENDATIONS}

1. To profile the antibiotic resistance pattern of bacteria isolated in ants from different tertiary hospitals with emphasis on including critical care units as sampling points.

2. To consider elucidating linkage between existing policies and guidelines and implementation of sanitation standards and pest control protocols.

\section{REFERENCES}

1. Boursaux-Eude C, Gross R. New insights into symbiotic associations between ants and bacteria. Research in Microbiology. 2000; 151(7): 513-519. DOI: 10.1016/s0923-2508(00)00221-7

2. Malik K, Arshad A, Jamil A. Isolation and identification of pathogenic microorganisms on the external body parts of carpenter ant (Camponotus pennsylvanicus) collected from kitchens. Journal of Pharmacy and Biological Sciences. 2013; 7(5): 83-86. DOI: 10.9790/3008-0758386

3. Moreira D, Morais VD, Vieira-da-Motta O, Campos-Farinha AE, Tonhasca Jr A. Ants as carriers of antibiotic-resistant bacteria in hospitals. Neotropical Entomology. 2005; 34(6): 999-1006. DOI: /10.1016/j.jhin.2016.01.010 
4. Rodovalho CM, Santos AL, Marcolino MT, Bonetti AM, Brandeburgo MA. Urban ants and transportation of nosocomial bacteria. Neotropical Entomology. 2007; 36(3): 454-858. DOI: 10.1590/s1519-566x2007000300014

5. Silva NC, Paiva MM, Pesquero MA, Carneiro LC. Assessment of ants as bacterial vector in houses. African Journal of Microbiology Research. 2014; 8(13): 1413-1418. D0I: 10.5897/ajmr2013.6430

6. Khan HA, Ahmad A, Mehboob R. Nosocomial infections and their control strategies. Asian Pacific Journal of Tropical Biomedicine. 2015; 5(7): 509-514.

7. General DM, Alpert GD. A synoptic review of the ant genera (Hymenoptera, Formicidae) of the philippines; 2012. Available from: goo.gl/CfyRhz

8. Garcia FR, Lise F. Ants associated with pathogenic microorganisms in Brazilian hospitals: Attention to a silent vector. Acta Scientiarum Health Sciences. 2013; 35(1): 34-40. D0I: 10.4025/actascihealthsci.v35i1.10471

9. Máximo HJ, Felizatti HL, Ceccato M, Cintra-Socolowski P, Beretta AL. Ants as vectors of pathogenic microorganisms in a hospital in São Paulo county, Brazil. Bio Med Central Research Notes. 2014; 7(1): 554-560.

10. Rodríguez PL, Flórez CV, Russo A, Domínguez HY, Valencia JA, Arboleda VJ, Valle-Molinares RH. The ghost ant tapinoma melanocephalum (Formicidae) as mechanical vector of clinically important bacteria; 2016.

Available from: goo.gl/iNXPpy

11. Pesquero MA, Carneiro LC, Pires DD. Insect/Bacteria association and nosocomial infection; 2012.

Available from: goo.gl/78ZEYa

12. Lima WR, Marques SG, Rodrigues FS, Rebelo JM. Ants in a hospital environment and their potential as mechanical bacterial vectors. Revista da Sociedade Brasileira de Medicina Tropical. 2013; 46(5): 637-640.

DOI: $10.1590 / 0037-8682-1607-2013$

13. Tille P. Bailey and scott's diagnostic microbiology. St. Louis, USA: Elsevier Health Sciences, 2013.

14. Akre RD, Antonelli AL. Pharaoh ant; 2003. Available from: goo.gl/Eiy4Wc

15. Davis MA. Invasion biology. Oxford, UK: Oxford University Press, 2009.

16. Cremer S, Ugelvig LV, Lommen ST, Petersen KS, Pedersen JS. Attack of the invasive garden ant: Aggression behaviour of lasius neglectus (Hymenoptera, Formicidae) against native Lasius species in Spain. Myrmecologische Nachrichten. 2006; 9(2): 13-19.

17. Nickerson JC, Harris DL. Featured creatures. Florida department of agriculture and consumer services (Division of plant industry); 2003. Available from: goo.gl/MQa1Ux

18. Graystock P, Hughes WO. Disease resistance in a weaver ant, Polyrhachis dives, and the role of antibiotic-producing glands. Behavioral Ecology and Sociobiology. 2011; 65(12): 2319-227. DOI: 10.1007/s00265-011-1242-y

19. Johnson RN, Agapow PM, Crozier RH. A tree island approach to inferring phylogeny in the ant subfamily Formicinae, with especial reference to the evolution of weaving. Molecular Phylogenetics and Evolution. 2003; 29(2): 317-330.

DOI: $10.1016 / \mathrm{s} 1055-7903(03) 00114-3$

20. Manchanda V, Sanchaita S, Singh NP. Multidrug resistant acinetobacter. Journal of Global Infectious Diseases. 2010; 2(3): 291-300.

21. Pontieri L. Discrimination behavior in the supercolonial pharaoh ant. [Doctoral dissertation]. Department of Biology, Faculty of Science, Denmark, DK, University of Copenhagen; 2014.

22. Akino T, Yamamura K, Wakamura S, Yamaoka R. Direct behavioral evidence for hydrocarbons as nestmate recognition cues in Formica japonica (Hymenoptera: Formicidae). Applied Entomology and Zoology. 2004; 39(3): 381-387.

DOI: $10.1303 /$ aez.2004.381

23. National Institute of Metrology, Quality and Technology. Programme of product analysis: Report on examination for general purpose disinfectants; 2008. Available from: goo.gl/bvQvGm 